\title{
Impacts of Educational Intervention on Cervical Cancer Knowledge Among Health Care Students in a Tertiary Institution
}

\author{
Winifred Ojieabu ${ }^{1, *}$, Christabel Ojieabu ${ }^{2}$, Shakirat Bello ${ }^{3}$, Frederick Oseji ${ }^{4}$ \\ ${ }^{1}$ Department of Clinical Pharmacy and Biopharmacy, Faculty of Pharmacy, Olabisi Onabanjo University, \\ Sagamu Campus, Sagamu, Ogun State, Nigeria. \\ 2Obafemi Awolowo College of Health Science, Olabisi Onabanjo University, Sagamu Campus, Sagamu, Ogun \\ State, Nigeria. \\ ${ }^{3}$ Department of Clinical Pharmacy and Pharmacy Practice, Faculty of Pharmaceutical Sciences, University of \\ Ilorin, Ilorin, Nigeria. \\ ${ }^{4}$ Department of Clinical Pharmacy and Pharmacy Practice, Igbinedion University, Okada, Edo State, Nigeria.
}

\begin{abstract}
Authors' Contributions
1 Conception \& Study Design, Data Collection

\& Processing, Data Analysis and/or Interpretation, Drafting of Manuscript, Critical Review.

2 Conception \& Study Design, Data Collection \& Processing, Data Analysis and/or Interpretation, Critical Review.

3 \& 4 Conception \& Study Design, Data Analysis and/or Interpretation, Drafting of Manuscript, Critical Review.
\end{abstract}

\begin{tabular}{l}
\hline Acknowledgement \\
We sincerely appreciate the respondents who \\
participated in this study. \\
\hline Article info. \\
Received: June 01, 2020 \\
Accepted: January 25, 2021 \\
\hline Funding Source: Nil \\
Conflict of Interest: Nil \\
\hline Cite this article: Ojieabu W, Ojieabu C, Bello \\
S, Oseji F. Impacts of Educational Intervention \\
on Cervical Cancer Knowledge Among Health \\
Care Students in a Tertiary Institution. RADS J \\
Pharm Pharm Sci. 2020; 8(4):216-221.
\end{tabular}

*Address of Correspondence Author: natbelpharmacy@yahoo.com

\section{A B S TR A C T}

Background: Cervical cancer (CC) is the commonest female cancer in the developing nations. The virus behind CC is Human papillomavirus (HPV). In sub-Saharan Africa, high mortality arises from low public awareness and knowledge about the disease.

Objective: This study assessed the effectiveness of educational intervention as a means to improve cervical cancer knowledge among health care students.

Methodology: Year 4-5 medical and pharmacy students of Olabisi Onabanjo University (OOU) took part in a quasi-experimental study. An anonymous pretested self-administered questionnaire was used to collect data at pre-and post-intervention sessions for comparison after one and half hours of educational intervention lecture. Data were analyzed with SPSS version 16. P $\leq 0.05$ was considered significant.

Results: Age range 21-26 years was $85.0 \%$, male to female: 1.1:1.2. Majority $(63.1 \%)$ had heard of CC prior to the intervention, gender it affects $(50.6 \%)$, stages of cervical cancer (26.3\%). Infection with HPV (14.4\%), genetics $(61.9 \%)$, having many children (15.0\%). Pap test is to detect early signs of CC (41.3\%), pap test not needed after HPV vaccine (20.0\%), healthy adult women have pap test every three years $(21.3 \%)$, All the scores significantly increased after post-intervention.

Conclusion: Educational intervention was successful in improving CC knowledge among participants.

Keywords: Cervical cancer, Knowledge, Educational intervention, Impacts, Students.

\section{INTRODUCTION}

Cervical cancer (CC) has certainly become a disease of great significance worldwide. It is the commonest female cancer, especially in the developing nations
[1,2]. According to a previous study [3], incidence of cervical cancer in developing countries is likely to increase to 588,922 by 2025 . In sub-Saharan Africa, there is high cancer mortality arising from low public awareness and knowledge about the disease as well 
as among primary health-care providers which are needed for timely uptake for its screening and early detection [4]. In developed nations, cervical cancer age-standardized incidence rate is 5.0 per 100,000 as compared to 8.0 per 100,000 in developing nations [5]. It is estimated that about 19,440 new cervical cancer cases will be recorded in Nigeria by year 2025 [3]. Important factors such as low educational levels, gender inequalities, poverty, early sexual debut inadequate or non-availability of screening services, increased prevalence of Human Papillomavirus infection, HIV/AIDS as well as other sexually transmitted diseases and related matters have been found to contribute to increased incidence of cervical cancer [ 6,7].

The virus behind cervical cancer is Human papillomavirus (HPV), a sexually transmitted infection found in young women less than 25 years of age [8]. One way to prevent cervical cancer is to vaccinate young girls against the causative organism (HPV) before sexual debut [9]. In population-based cervical cancer screening programs, use of Human papillomavirus testing method has been found to be very effective [10]. Also in the developed nations of the world, cervical cancer incidence has been reduced by above $70 \%$ through Papaniculao (PAP) smear test which has been grossly insufficient in most of the developing countries like Nigeria [2].

\section{Significance of the Study}

There is need to improve the knowledge of health care professionals regarding their various areas of practice as they are the main consultants in health care matters. Improved knowledge of disease states of these professionals will enable them build up a satisfactory and effective practice experience. This study therefore aimed to assess the Seffectiveness of an educational intervention as a means to improve cervical cancer knowledge among health care students in a Tertiary Institution in South-Western Nigeria.

\section{MATERIALS AND METHODS}

We invited $4^{\text {th }}-5^{\text {th }}$ year students of Faculty of Pharmacy and Obafemi Awolowo College of health sciences of Olabisi Onabanjo University (OOU), Ogun State, Nigeria to take part in a quasi-experimental study where their pre-and post-intervention responses were compared. The two faculties are located within the premises of Olabisi Onabanjo University Teaching
Hospital (OOUTH), Sagamu for ease of students' clinical rotations. The purpose and the form of the study were explained to them before the commencement of the study. Those who declined participation were allowed to leave the venue of the study. We used an anonymous self-administered questionnaire which was pretested among non-health care students for clarity to obtain data from the students. The questionnaire consisted of the following sections: socio-demographic characteristics of respondents, knowledge of cervical cancer and risk factors and knowledge of cervical cancer tests.

\section{Intervention and Administration of Questionnaire}

The anonymous questionnaire was first administered to collect pre-intervention data. This was followed with an hour and half lecture on knowledge of cervical cancer, risk factors, prevention, uses of Human Papilloma Virus (HPV) vaccine and Papaniculao (PAP) smear test. This was then followed by the administration of the exact type of questionnaire used for the pre-intervention data collection to obtain the post-intervention data.

\section{Data Analysis}

Data were checked for accuracy before being entered into Microsoft Excel for sorting. Further analysis was performed with Statistical Package for Social Sciences (SPSS) software, version 16, (Chicago, Illinois), using descriptive and comparative analyses. Comparison of proportions was carried out with Chisquare and Fisher's exact tests. $\mathrm{P} \leq 0.05$ was considered statistically significant.

\section{RESULTS}

\section{Demographic Characteristics of Respondents}

The number that honoured our invitation to participate was 166 but only 160 correctly filled the questionnaire and hence used for the study (response rate=96.4\%). Male to female ratio was 1.1:1.2. Age range 21-26 years had the highest representation (85.0\%), while pharmacy students and singles were $60.6 \%$ and 95.0\% respectively $(P<0.05)$ (Table 1$)$.

\section{Knowledge of Cervical Cancer and Risk Factors Among Respondents}

Majority (63.1\%) had heard of cervical cancer prior to the intervention, gender it affects (50.6\%), stages of cervical cancer (26.3). On cervical cancer risk factors: infection with HPV (14.4\%), genetics (61.9\%) and 
having many children (15.0\%). All the post intervention scores significantly increased to between 93.1\%-100\%, $\mathrm{P}<0.05$, (Table 2).

\section{Knowledge of HPV Vaccine and Cervical Cancer Tests Among Respondents}

Knowledge scores at pre-intervention regarding HPV vaccine were: HPV vaccine prevents cervical cancer and genital warts (33.1\%), HPV vaccine is administered in 3 doses $(36.3 \%)$. Other responses were: Pap test is to detect early signs of cervical cancer $(41.3 \%)$, pap test is not needed after HPV vaccine $(20.0 \%)$ and healthy adult women have pap test every three years (21.3\%), These significantly increased at post-intervention to between $91.3 \%$ 100.0\%, $\mathrm{P}<0.05$, (Table 3).

Table 1. Demographic Characteristics of Respondents $(\mathrm{N}=160)$.

\begin{tabular}{|c|c|c|c|}
\hline Variables & Frequency & Percentage & P- Value \\
\hline Gender & & & \\
\hline Male & 77 & 48.1 & 0.772 \\
\hline Female & 83 & 51.9 & \\
\hline Age & & & $<0.000^{*}$ \\
\hline$<21$ & 12 & 7.5 & \\
\hline $21-26$ & 136 & 85.0 & \\
\hline $27-30$ & 7 & 4.4 & \\
\hline$>30$ & 5 & 3.1 & $0.033^{*}$ \\
\hline Course of study & & & \\
\hline Medicine & 63 & 39.4 & $<0.000^{*}$ \\
\hline Pharmacy & 97 & 60.6 & \\
\hline Marital status & 152 & & \\
\hline Single & 8 & 95.0 & \\
\hline Married & & & \\
\hline
\end{tabular}

${ }^{*}=$ Statistically Significant

Table 2. Knowledge of Cervical Cancer and Risk Factors Among Respondents ( $N=160)$.

\begin{tabular}{|c|c|c|c|}
\hline \multirow{2}{*}{$\begin{array}{c}\text { Cervical cancer knowledge } \\
\text { domain }\end{array}$} & \multicolumn{2}{|c|}{ Those who answered correctly } & \multirow{2}{*}{ P-Value } \\
\cline { 2 - 3 } & Pre-Intervention 160 (\%) & Post-Intervention 160 (\%) & \\
\hline Heard of cervical cancer? & $101(63.1)$ & $160(100.0)$ & $0.007^{*}$ \\
\hline Affect any part other than the cervix? & $30(18.8)$ & $155(96.9)$ & $<0.000^{*}$ \\
\hline What gender does it affect? & $81(50.6)$ & $160(100.0)$ & $0.000^{*}$ \\
\hline What population is susceptible? & $26(16.3)$ & $160(100.0)$ & $<0.000^{*}$ \\
\hline How many stages of cervical cancer? & $42(26.3)$ & $154(96.3)$ & $<0.000^{*}$ \\
\hline Cervical cancer risk factors & & & $<0.000^{*}$ \\
\hline Infection with HPV & $23(14.4)$ & $158(98.8)$ & $0.006^{*}$ \\
\hline Genetics & $99(61.9)$ & $160(100.0)$ & $<0.000^{*}$ \\
\hline Being a smoker & $64(40.0)$ & $154(96.3)$ & $<0.000^{*}$ \\
\hline Long-term use of contraceptive pills & $29(18.1)$ & $160(100.0)$ & $<0.000^{*}$ \\
\hline Early onset of sexual intercourse & $27(16.9)$ & $160(100.0)$ & $<0.000^{*}$ \\
\hline Having many sexual partners & $33(20.6)$ & $160(100.0)$ & $<0.000^{*}$ \\
\hline Having many children & $24(15.0)$ & $149(93.1)$ & \\
\hline
\end{tabular}

${ }^{*}=$ Statistically Significant 
Table 3. Knowledge of HPV Vaccine and Cervical Cancer Tests Among Respondents ( $\mathrm{N}=160$ ).

\begin{tabular}{|c|c|c|c|}
\hline \multirow[b]{2}{*}{ Knowledge of HPV vaccine and cervical cancer tests } & \multicolumn{2}{|c|}{ Those who answered correctly } & \multirow[b]{2}{*}{ P-Value } \\
\hline & $\begin{array}{c}\text { Pre-Intervention } \\
160(\%)\end{array}$ & $\begin{array}{l}\text { Post-Intervention } \\
160(\%)\end{array}$ & \\
\hline Heard of HPV vaccine & $57(35.6)$ & $160(100.0)$ & $<0.000^{*}$ \\
\hline HPV vaccine prevents cervical cancer and genital warts & $53(33.1)$ & $160(100.0)$ & $<0.000^{*}$ \\
\hline HPV vaccine is administered in 3 doses & $58(36.3)$ & $160(100.0)$ & $0.001^{*}$ \\
\hline Given to girls from 10 years up before sexual debut & $45(28.1)$ & $160(100.0)$ & $<0.000^{*}$ \\
\hline Pap test is to detect early signs of cervical cancer & $66(41.3)$ & $146(91.3)$ & $<0.000^{*}$ \\
\hline Healthy adult women have pap test every three years & $34(21.3)$ & $151(94.4)$ & $<0.000^{*}$ \\
\hline Pap test is not needed after HPV vaccine & $32(20.0)$ & $154(96.3)$ & $<0.000^{*}$ \\
\hline $\begin{array}{l}\text { Pap test is necessary even if there is no family history of } \\
\text { cancer }\end{array}$ & $58(36.3)$ & $160(100.0)$ & $<0.000^{*}$ \\
\hline
\end{tabular}

${ }^{*}=$ Statistically Significant

\section{DISCUSSION}

The students showed below average knowledge level at pre-intervention stage in their response to all the twenty questions featured in this study except in three of them where they had above average scores. This is similar to other studies $[11,12]$ but higher than that gotten in another research [13]. Roughly three thirds of our respondents had heard about cervical cancer prior to the commencement of the intervention study, a finding likened to a previous one [14] but differed from another where majority of the students had never heard about cervical cancer before the intervention [15]. In particular, the knowledge base of the students in respect to the other questions on cervical cancer knowledge domain was poor on the average as three out of the six questions were below $30 \%$, a study different from an earlier one where a sizable proportion was said to have adequate knowledge [15]. The difference could be due to the fact that their population comprised of practicing health care professionals as compared to our student population.

Knowledge about cervical risk factors was also very poor as no domain obtained up to average knowledge score at the pre-intervention response. This is similar to previous ones $[15,16]$. Knowledge of risk factors is very important in disease management as it forms the basis of the preventive measures especially when it relates to chronic diseases. Less than a third of the respondents have heard of HPV vaccine at preintervention session. This was lower than results from previous studies [17,18]. Knowledge on the preventive function of HPV vaccine was also not known to the majority of the respondents as only few agreed it is for prevention against cervical cancer and genital warts. The same level of ignorance applied to pap smear test. The difference between HPV vaccine and pap smear test should be understood properly by the students for the benefit of their practice. The HPV vaccine does not protect the receiver $100 \%$ against all the cervical cancer causing genotypes $[19,20]$. It is therefore required that the recipient of HPV vaccine would usually need to do pap smear test regularly for early detection of pre-cancerous lesions. This we actually laid emphasis on during our intervention lecture.

There was however statistically significant improvement in the percentage scores between the pre-intervention and post-intervention responses by the students across board. This is an indication of the success of educational intervention strategy used in this study which have also been recorded by some previous studies [21,22]. A possible explanation for this overall improvement in the post-intervention maybe that the students have gained more knowledge of cervical cancer from the intervention lecture in addition to the rudimentary knowledge as health care students.

\section{CONCLUSION}

Our respondents' knowledge improved from the least pre-intervention score of less than $15 \%$ to above $90 \%$ in all the areas assessed. Educational interventions 
have been found to be successful in many studies especially among students and can be used to bridge knowledge gaps. With these encouraging results, educational interventions could be made an integral part of cervical cancer prevention strategy.

\section{Authors' Contribution}

All the authors contributed significantly to this research and also read the manuscript before its submission.

\section{Conflicts of interest}

Individual author declares no conflicts of interest.

\section{REFERENCES}

1. Parkin DM, Whelan SL, Ferlay J, Storm H. Cancer incidence in five continents. IARC Cancer. Base No 7. 2005. $11^{\text {th }}$ February 2013; Volumes I to VIII, 2013. Available from: http://www.iacr.com.fr/statist.htm.

2. Sankaranarayanan R, Budukh AM, Rajkumar R. Effective screening programmes for cervical cancer in low- and middle-income developing countries. Bull World Health Organ. 2001; 79:95462. DOI: $10.1590 / S 0042-96862001001000009$.

3. Ferlay J, Soerjomataram I, Ervik M, Dikshit R, Eser S, Mathers C, Rebelo M, Parkin DM,

Forman D, Bray F. GLOBOCAN 2012 v1.0, Cancer Incidence and Mortality Worldwide: IARC Cancer Base No. 11 [Internet]. Lyon, France: International Agency for Research on Cancer; 2013. Available from: http://globocan.iarc.fr. Accessed: 27/5/2020.

4. Imran $\mathrm{O}$ Morhason-Bello, Folakemi Odedina, Timothy R Rebbeck, Joe Harford, Jean-Marie Dangou, Lynette Denny, Isaac F Adewole. Cancer Control in Africa 1, Challenges and opportunities in cancer control in Africa: a perspective from the African Organisation for Research and Training in Cancer. Lancet Oncol. 2013; 14(4): e142-51. DOI:10.1016/S1470-2045(12)70482-5. Accessed: 15/4/2020.

5. Global Burden of Disease Cancer Collaboration, Fitzmaurice C, Dicker D, Pain A, Hamavid H, Moradi-Lakeh M, Macintyre MF. et al. The Global Burden of Cancer 2013. JAMA Oncol. 2015; 1(4):505-27. https://doi.org/10.1001/ jamaoncol.2015.0735 PMID: 26181261.

6. Twinomujuni C, Nuwaha F, Babirye JN. Understanding the Low level of cervical cancer screening in Masaka Uganda using the ASE model: A community-based survey. PLoS ONE 10
(6): $\quad$ e0128498.2015.

DOI: 10.1371/journal.pone.0128498.

7. Mwaka AD, Orach CG, Were EM, Lyratzopoulos G, Wabinga H, Roland M. (2015) Awareness of cervical cancer risk factors and symptoms: Crosssectional community survey in post-conflict northern Uganda. Health Expect. 2015; 19(4):85467. DOI:10.1111/hex.12382. PMID:26205470; PMCID:PMC4957614

8. Stanley M. Pathology and epidemiology of HPV infection in females. Gynecol Oncol. 2010; 117(2Suppl):S5-10.

DOI:10.1016/j.ygyno.2010.01.024. PMID:20304221.

9. Gaffikin L, Blumenthal PD, Emerson M, Limpaphayom KK, Royal Thai College of Obstetricians and Gynaecologists (RTCOG)/JHPIEGO Cervical Cancer Prevention Group: Safety, acceptability, and feasibility of a single-visit approach to cervical cancer prevention in rural Thailand: a demonstration project. Lancet. 2003; 361:814-820. DOI:10.1016/S01406736(03)12707-9.

10. Campos NG, Tsu V, Jeronimo J, Mvundura M, Kim JJ. Evidence-based policy choices for efficient and equitable cervical cancer screening programs in low-resource settings. Cancer Med. 2017. https://doi.org/10.1002/cam4.1123 PMID: 28707435.

11. Elmaged Elrufie ESA, Yousif KI1, Abdelrahman Mohmed Kambal. Effect of Educational Program on Saudi, Women' Knowledge, Attitude Regarding Cervical Cancer and Early Detection by Pap Test. Nursing \& Healthcare International Journal. 2017; 1(2): 000108.

12. Hoque ME. Cervical Cancer Awareness and Preventive Behaviour among Female University Students in South Africa. Asian Pac J. of Cancer Prev. 2010; 11(1):127-130.

13. Poonam R Naik, Nagaraj $K$, Abhaya Subhashrao Nirgude. Awareness of Cervical Cancer and Effectiveness of Educational Intervention Programme among Nursing Students in a Rural Area of Andhra Pradesh. Healthline. 2012; 3(2):41-45.

14. Bessler $P$, Aung $M$, Jolly $P$. Factors affecting uptake of cervical cancer screening among clinic attendees in Trelawny, Jamaica. Cancer Control. 2007; $\quad$ 14(4):396-404. DOI:10.1177/107327480701400410. PMID: 17914340.

15. Sado AE, Ezeanochie M, Nwaneri DU, Ogboghodo BC, Eregie CO, Oviawe O, Famuyiwa O. Effect of Training on Knowledge about Cervical Cancer and 
Human Papiloma Virus Vaccine among Health Care Personnel in Benin City. J Com Med Pry Health Care. 2018; 30(1):58-65.

16. Kress CM, Shawling L, Owen-Smith AA, Desalegn D, Blumberg HM, Goedken J. Knowledge, attitudes and practices regarding cervical cancer and screening among Ethiopian health care workers. Int J Women's Health. 2015; 7:765-772. DOI: 10.2147/IJWH.S85138. PMID: 26261427, PMCID: PMC4527576.

17. Ugwu EO, Obi SN, Ezechukwu PC, Okafor II, Ugwu AO. Acceptability of Human papilloma virus vaccine and cervical cancer screening among female health care workers in Enugu, Southeast Nigeria. Nig J Clin Pract. 2013; 16(2):249-252. DOI: 10.4103/1119-3077.110141. PMID: 23563471.

18. Makwe CC, Anorlu RI. Knowledge of and attitude toward Human papillomavirus infection and vaccines among female nurses at a tertiary hospital in Nigeria. Int J Women Health. 2011; 3:313-317. DOI: 10.2147/IJWH.S22792.Epub 2011 Sep 13. PMID: 21976985; PMCID: PMC3181212.

19. De Vincenzo R, Conte C, Ricci C, Scambia G, Capelli G. Long-term efficacy and safety of human papilloma virus vaccination. Int $\mathrm{J}$ Womens Health.
2014; 6:999-1010. DOI:10.2147/IJWH.S50365. PMCID: PMC4262378 PMID: 25587221.

20. Tomar A, Kushwah A. Advances in human papilloma virus vaccines: a review. Int $\mathrm{J}$ Basic Clin Pharmacol. 2014; 3(1):37-43. https://www.ijbcp.com/index.php/ijbcp/article/view/ 942.

21. Prakash M Naregal, Vaishali R Mohite, Anagha V Katti, Prabhuswami Hiremath, Mahesh Chendake. Effectiveness of Planned Teaching Programme on Knowledge Regarding Cervical Cancer Among Women. Asian J Pharm Clin Res. Vol 10, Issue 2. 2017.

DOI:https://doi.org/10.22159/ajpcr.2017.v10i2.157 22.

22. Choma K, McKeever AE. Cervical Cancer Screening in Adolescents: An Evidence-Based Internet Education Program for Practice Improvement among Advanced Practice Nurses. Worldviews on Evidence-Based Nursing. 2015;12(1):51-60. DOl:10.1111/wvn.12071.Epub 2014 Dec 13. PMID:25495998. 